\title{
JENDRAL HOEGENG IMAM SANTOSO: KAPOLRI JUJUR, DISIPLIN DAN SEDERHANA SEBAGAI TELADAN GENERASI MUDA
}

\author{
JENDRAL HOEGENG IMAM SANTOSO: KAPOLRI HONEST, \\ DISCIPLINE AND SIMPLE EXAMPLES OF YOUNG GENERATION
}

\author{
Nur Hidayati $^{1}$, Anny Wahyuni ${ }^{2}$, Budi Purnomo ${ }^{3}$ \\ 1,2,3 Pendidikan Sejarah, FKIP, Universitas Jambi \\ ${ }^{1}$ nurhidayatii255@gmail.com
}

\begin{abstract}
Abstrak : Jenderal Hoegeng Iman Santoso adalah Kapolri pada tahun 1968 - 1971. Ia adalah putra bangsa yang lahir di Pekalongan pada tanggal 14 Oktober 1921. Penelitian ini menggunakan metode penelitian sejarah menurut Daliman yang terdiri dari dari empat langkah, yaitu: 1) Heurustik (pengumpulan data), 2) Kritik Sumber (pengujian), 3) Interpretasi (Analisis), 4) Historiografi (Sejarah Penulisan). Hasil penelitian ini adalah 1) Biografi Hoegeng Iman Santoso 2) Jejak Karir Hoegeng Iman Santoso 3) Karakter Hoegeng yang dapat ditiru oleh generasi muda: a) kejujuran yaitu perilaku dalam suatu usaha yang membuatnya dapat diandalkan dalam perkataan, tindakan dan kegiatan, kejujuran hoegeng harus dijadikan panutan bagi generasi muda b) disiplin waktu menentukan kefasihan manusia dalam mencapai sesuatu yang diinginkannya c) kesederhanaan merupakan tindakan yang selaras dengan kondisi sebenarnya..
\end{abstract}

Kata kunci: Hoegeng Iman Santoso, Kejujuran, Disiplin, Kesederhanaan.

\begin{abstract}
General Hoegeng Iman Santoso was the Chief of the Indonesian National Police (Kapolri) in 1968 - 1971. He is a son of the nation who was born in Pekalongan on October 14, 1921. This research uses the historical research method according to Daliman which consists of four steps, namely: 1) Heurustik ( data collection), 2) Source Criticism (testing), 3) Interpretation (Analysis), 4) Historiography (Writing History). The results of this study are 1) Biography of Hoegeng Iman Santoso 2) Career Tracks of Hoegeng Iman Santoso 3) Hoegeng's characters that can be imitated by the younger generation: a) honesty, namely behavior in an effort that makes him dependable in words, actions and activities, honesty Hoegeng should be used as a role model for the younger generation b) time discipline determines human fluency in achieving something he wants c) simplicity is an act that is in sync with actual conditions.
\end{abstract}

Keywords: Hoegeng Iman Santoso, Honesty, Discipline, Simplicity. 


\section{PENDAHULUAN}

Penguatan pendidikan Karakter (PPK) merupakan kebijakan pendidikan yang tujuan utamanya untuk implementasi nawacita presiden Joko Widodo dalam sistem pendidikan nasional. Kebijakan PPK terintegrasi dalam Gerakan Nasional Revolusi mental (GNRM) yang merupakan perubahan cara berfikir, bersikap dan bertindak menjadi lebih baik. Nilai utama yang diusung dalam PPK adalah religius, mandiri, gotong royong, integritas.nilai PPK ini di integrasikan melalui sistem pendidikan nasional agar diketahui, dipahami, dan diterapkan diseluruh sendi kehidupan di sekolah serta masyarakat (Kemdikbud, $2018: 7$ - 9)

PPK ini lahir karena kesadaran akan tantangan ke depan yang semakin kompleks seperti maraknya peristiwa-peristiwa korupsi di pejabat pemerintahan. PPK ini hadir sebagai harapan untuk masa depan agar lembaga-lembaga pendidikan mempersipakan peserta didik dari segi keilmuan dan kepribadiannya. Kepribadian ini berupa nilai moral, spritual dan keilmuan. PPK untuk zaman sekarang ini sangat di butuhkan berdasarkan fenomena yang terjadi di Indonesia seperti yang di muat oleh lembaga survei kosupsi dunia yang bernama Tranparency International Indonesia (TII).

Tranparency International Indonesia (TII) lembaga survei korupsi dunia pada 2020 menyatakan Indonesia menduduki peringkat 102 dari 180 negara yang disurvei. Peringkat tersebut sudah turun dibandingkan dengan survei yang dilakukan pada tahun 2019 dimana Indonesia menduduki peringkat 85 ( Rahmadan Kompas.Com 28 Januari 2021). Faktanya 75 tahun sudah Indonesia merdeka tetapi permasalahan korupsi belum dapat dituntaskan. Dibuktikan dengan masih banyak para pejabat dan wakil rakyat yang melakukan tindak korupsi seperti kasus korupsi dana bansos yang dilakukan menteri sosial Juliari Batubara, mantan menteri pemuda dan olahraga Imam Nahrawi yang tersangkut kasus suap dana hibah KONI dan masih banyak tokoh - tokoh lainnya yang terlibat korupsi.

Korupsi yang terjadi di lingkaran pejabat pemerintahan Republik Indonesia membuktikan bahwa masyarakatnya masih belum memiliki sikap yang baik dan terjadinya degradasi moral. Sikap yang baik dibentuk melalui pendidikan karakter. Pendidikan karakter menurut Umar Baradja dalam (Hasyim 2015:168) adalah serangkaian konsep dasar dalam membentuk sifat, karakter, watak yang harus dimiliki dan dijadikan kebiasaan oleh anak-anak, remaja, dewasa dan usia lanjut. Maka penguatan pendidikan karakter sangat penting diterapkan karena tidak terlepas dari fenomena sosial dewasa ini, yang dapat dilihat dari perilaku yang 
tidak berkarakter dan terdapat gejala yang menandai mulai tergerusnya karakter sebuah bangsa.

Penguatan pendidikan karakter memiliki tujuan yang pertama, membangun dan membekali peserta didik sebagai generasi emas Indonesia tahun 2045 guna menghadapi dinamika perubahan dimasa depan. Kedua mengembangkan platform pendidikan nasional yang meletakan pendidikan karakter sebagai jiwa utama dengan memperhatikan nilai keberagamaan kebudayaan Indonesia. Ketiga merivitalisasi dan memperkuat potensi serta kompetensi ekosistem pendidikan.

Penguatan Pendidikan karakter bisa di dapat melalui pembelajaran di sekolah salah satunya pembelajaran sejarah. Pembelajaran sejarah menurut Sapriya (dalam Zahro, Sumardi \& Marjono 2017:4) merupakan cabang ilmu pengetahuan yang menelaah tentang asal - usul dan perkembangan serta nilai - nilai kearifan yang dapat digunakan untuk melatih kecerdasan membentuk sikap watak dan kepribadian peserta didik. Pembelajaran sejarah yang terikat dengan kisah - kisah masa lalu dan tokoh yang terlibat dalam perjuangan kemerdekaan serta setelah kemerdekaan. Banyak tokoh - tokoh yang bisa dijadikan tauladan untuk pendidikan karakter peserta didik salah satunya Hoegeng.

Hoegeng merupakan Kapolri yang menjabat dari tahun 1968-1971. Hoegeng merupakan sosok yang disegani di kalangan kepolisian Republik Indonesia. Dia hanya menjabat tiga tahun sebagai Kapolri namun Hoegeng membawa perubahan besar dalam tubuh Kepolisian Republik Indonesia. Karakter tegas, jujur, sederhana, bersih dan memiliki integritas menjadikan beliau legenda di kepolisian. Salah satu fakta beliau mempunya sifat tegas dan bersih adalah ketika Hoegeng dirayu oleh seorang penguasa cantik keturunan Makasar-Tionghoa untuk kasus penyelundupan. Wanita ini meminta Hoegeng untuk tidak melanjutkan kasus penyelundupan ke pengadilan akan tetapi Hoegeng menolaknya.

Fakta diatas menunjukan bahwa Jendral Hoegeng merupakan figur yang terkenal dengan sifat kesederhanaanya, integritasnya dan kejujurannya selama hidupnya, Sudah selayaknya, tokoh seperti Jendral Hoegeng Iman Santoso harus dipopulerkan kembali kepada generasi muda yang akan melajutkan tongkat estafet kepemimpinan agar menjadi pemimpin yang baik, jujur, dan menjadi teladan publik serta tidak melakukan hal - hal yang menyimpang seperti korupsi.

Hoegeng dimata Abdurrahman Wahid atau yang biasa dikenal dengan Gus Dur menceritakan bahwa di Indonesia hanya ada tiga polisi yang tak bisa disuap : Patung Polisi, Jurnal Swadesi, Volume II Nomor 1 (Mei) 2021 
Polisi Tidur dan Hoegeng. Selain itu M. Jusuf Kalla juga mengutarakan bahwa Jendral Hoegeng adalah tokoh yang jujur, ia adalah sosok yang sederhana, yang tak punya apa - apa kecuali kejujuran itu sendiri (Suhartono, 2013).

Dari penjabaran diatas penulis tertarik melakukan penelitian tentang "Jendral Hoegeng Imam Santoso: Kapolri Jujur, Disiplin dan Sederhana Sebagai Teladan Generasi Muda". Agar generasi muda dapat menjadi sosok yang jujur, disiplin dan sedeharna.

\section{METODE}

Metode yang digunakan dalam penelitian ini adalah metode penelitian sejarah dengan menggunakan pendekatan studi pustaka. Studi pustaka ini dengan mengumpulkan data primer dan data sekunder dari buku, dekomen dan tulisan yang relevan dengan topik pembahasan. Menurut Daliman (2012) terdapat empat langkah dalam melakukan metode sejarah yaitu:

1. Heuristik (Pengumpulan data)

Kegiatan pengumpula data yang ilakukan oleh peneliti dengan mengunjungi berbagai pustaka, mengumpulkan buku - buku, dokumen, dan mengakses jurnal-jurnal yang relevan dengan pokok pembahasan. Sumber primer yang digunakan penulis yaitu buku yang berjudul Hoegeng Polisi Idaman dan kenyataan (sebuah autobiografi), dan sumber sekunder adalah buku yang berjudul Hoegeng Polisi dan Menteri Teladan, serta jurnal-jurnal dan koran yang membahas Hoegeng Iman Santoso.

2. Kritik Sumber (pengujian)

Kritik sumber digunakan untuk memperoleh kredibelitas dan keabsahan data. Kritik yang akan dilakukan terdiri dari kritik internal dan eksternal. Kritik internal pada penelitian ini dengan melihat latar belakang penulis baik dari segi usia dan sejauh mana penulis mengetahui kehidupan tokoh. Kritik eksternal mengacu pada penggunaan buku yang digunakan pada penelitian ini.

3. Interpretasi (Analisis)

Interpretasi merupakan suatu usaha penafsiran fakta sejarah atau bukti sejarah (Daliman 2012 :81). Maka interpertasi adalah kegiatan menganalisis yang didapatkan dari sumber yang sudah diverifikasi. Penafsiran dan pemberian makna pada hasil tulisan yang dibuat oleh penulis dari tahap kritik sumber. Karena sudah tersusun secara terstrutur kemudian dirumuskan dan muncul kesimpulan pada tahap ini. 
4. Historiografi (penulisan sejarah).

Berbagai sumber yang telah dikumpulkan,diseleksi,dianalisis serta melalui proses imajinasi berdasarkan fakta-fakta yang telah ditemukan. Hasil rekonstruksi tersebut peneliti tuangkan menjadi sebuah penulisan sejarah atau historiografi.

\section{HASIL DAN PEMBAHASAN}

\section{Biografi Hoegeng Iman Santoso}

Hoegeng Iman Santoso adalah Kepala Kepolisian Republik Indonesia pada tahun 1968 - 1971. Dikota Pekalongan tanggal 14 Oktober 1921 Hoegeng dilahirkan. Pekalongan adalah salah satu kota kecil yang berada ditepi laut utara Jawa Tengah, kira - kira 100 Kilometer dari kota Semarang. Tepatnya Hoegeng lahir dikampung Pesatean, suatu daerah yang dahulunya mencorakan suatu perkampungan Arab dan berada tidak jauh dari Bong Cina atau komplek pemakaman orang - orang Cina ( Yusra \& Ramadhan, 1993 :15).

Hoegeng lahir dari keluarga yang baik - baik ayahnya bernama Soekario Kario Hatmodjo yang merupakan orang Tegal, beliau adalah pegawai Hindia Belanda yang berkerja sebagai jaksa di landraad (Pengadilan Negeri). Ibunda Hoegeng Iman Santoso bernama Oemi Kalsoem orang Pemalang (Yusra \& Ramadhan, 1993). Orang tua Hoegeng mempunyai 3 orang anak, Hoegeng Iman santoso adalah putra sulung, dan kedua adiknya perempuan yang bernama Titi Soedjati dan yang bungsu adalah Soedjatmi.

Hoegeng Iman Santoso lebih suka dipanggil atau memakai nama Hoegeng saja. Nama yang lengkap terasa berat karena bobot atau idealisasinya. Hoegeng Iman Santoso masuk sekolah SD atau Hollandsch Inlandsche School (HIS) di Pemalang pada tahun 1927. Dari HIS Pemalang Hoegeng pindah ke HIS Pekalongan karena pada saat itu sang ayah (Soekario Kario Hatmodjo) dipindahkan tugas menjadi Hoofd jaksa di Pekalongan. Lulus dari HIS ditahun 1934 Hoegeng melanjutkan sekolahnya di Meer Uitgebreid Lager Onderwijs (MULO) atau sekolah yang sederajad dengan Sekolah Menengah Pertama (SMP) sekarang.

Setelah tamat MULO tahun 1937 Hoegeng melanjutkan sekolah ke Aglemeene Middlebare School (AMS) di Yogyakarta atau setara dengan Sekolah Menengah Atas (SMA) pada saat ini. Hoegeng mengambil jurusan A II dan lulus pada tahun 1940. Selanjutnya Hoegeng melanjutkan kuliah di Recht Hoge School (RHS) Sekolah Tinggi Hukum di Batavia. Namun pendidikan RHS tidak dapat diselesaikan karena Jepang sudah masuk Indonesia dan RHS ditutup (Sohartono, 2013). 
Ditutupnya RHS membawa Hoegeng pulang kembali ke Pekalongan. Awal kependudukan Jepang Hoegeng menjadi seorang pengangguran. Untuk mengisi waktu luang, akhirnya Hoegeng dan temannya Sohardjo Soerjobroto berjualan keliling menjual apa saja yang dapat dijual. Mereka berjualan tidak hanya di Pekalongan saja tetapi sampai ke daerah lain seperti Pati dan Semarang (Yusra \& Ramadhan, 1993).

Ketika kembali ke Pekalongan Hoegeng mendapat informasi terbukanya ruang bagi para pemuda Indonesia untuk bisa masuk kursus Polisi dengan salah satu syaratnya adalah minimal tamatan MULO. Polisi yang dibutuhkan sebanyak 11 orang. Dengan semangat jiwa muda yang berkobar Hoegeng mendaftarkan diri ia percaya karena Hoegeng merupakan alumi AMS dan Drop Out RHS mempunyai kesempatan yang besar untuk menjadi inspektur polisi. 130 orang yang mendaftar Hoegeng adalah salah satu yang terpilih menjadi inspektur kepolisian. Namun ternyata kusus tersebut hanya untuk Hoofd Agent Polisi dimana jabatannya dibawah pangkat Inspektur polisi kelas II.

Kursus dan latihan polisi ini diserahkan sepenuhnya kepada orang pribumi dibawah kepemimipanan Soemarto. Kursus sekolah ini bertempat di asrama polisi. Hoegeng dan teman - temannya yang di terima sabagai siswa mendapat gaji Rp 32 dan mendapat seragam serta senjata. Sekolah kepolisian ini berlangsung selama kurang lebih 6 bulan. Siswa dari sekolah tersebut merupakan hasil produk sekolah kepolisian pada zaman kependudukan Jepang kemudian menjadi perwira kepolisian Republik Indonesia pada gelombang pertama.

Pada usia 21 tahun Hoegeng di tarik untuk bekerja di kantor Jawatan Kepolisian di Keresidenan Pekalongan namun pada saat itu Hoegeng berpikiran untuk keluar saja dan ingin melajutkan sekolahnya menjadi hakim. Namun pada saat itu pak Soemarto mendaftarkan Hoegeng ke pendidikan untuk kader kepolisian di Sukabumi dengan tidak semangat Hoegeng menjalankan pendidikan tersebut. Namun sangat disayangkan setelah pendidikan itu selesai dilakukan hanya diberi pangkat Minarai Junsabutyo yang justru lebih rendah dari pangkat sebelumnya.

\section{Jejak Karier Hoegeng Iman Santoso}

Pada tanggal 17 Agustus 1945 saat proklamasi digaungkan, Hoegeng Iman Santoso berdinas di kepolisian Kota Semarang. Hoegeng terus meneruskan pendidikan kepolisiannya sampai pada akhirnya Hoegeng menjadi Mahasiswa Perguruan Tinggi Ilmu Kepolisian (PTIK) dan disisi lain menjalankan tugasnya sebagai polisi bagian lalu lintas dan lain - lain di Markas 
Besar Angkatan Kepolisian. Pangkat Hoegeng saat itu adalah Arjun Komisaris Polisi (AKP). Dan Hoegeng lulus PTIK pada tahun 1952.

Setelah lulus dari PTIK Hoegeng bekerja di wilayah kepolisian Jawa Timur selaku wakil kepala direktorat DPKN (Dinas Pengawasan Keamanan Negara). Selanjutnya tahun 1956 Hoegeng Iman Santoso ditugaskan ke Medan Sumatera Utara. Di Medan pada saat itu kondisinya sangat banyak kasus kejahatan mulai dari penyelundupan, perjudian dan perampokan. Medan bukanlah wilayah yang mudah untuk bekerja karena ujiannya yang sangat besar, terutama untuk para polisi yang jujur dan tidak mudah untuk disuap seperti Hoegeng namun sangat menarik untuk polisi yang mudah melanggar hukum. (Suhartono, 2013).

Karena Hoegeng yang teguh pendirian dan tidak bisa diajak kompromi oleh para penyeludup, Hoegeng sering menghadapi ancaman pembunuhan dan mejadi sasaran para penembak jitu. Tahun 1960 Hoegeng ditarik pulang ke Jakarta. Pulang dari Medan Hoegeng tidak memiliki pekerjaan dan mengganggur, waktunya banyak dihabiskan untuk melukis, bermusik dan berkumpul bersama keluarga (Suhartono, 2013).

Pada 19 Januari 1961 secara resmi Hoegeng dilantik menjadi Kepala Jawatan Imigrasi. Ini adalah pekerjaan pertama Hoegeng diluar kepolisian. Namun akhirnya pada bulan Juni 1965 ia mengundurkan diri (Suhartono, 2013). Kemudian pada tahun 1965 didalam Kabinet Dwikora I Hoegeng dilantik menjadi Menteri Iuran Negara. Dan pernah menjabat sebagai menteri/sekretaris presidium kabinet. Pada saat kabinet Dwikora II Hoegeng diamanahkan menjadi Menteri Urusan Iuran Negara yang berjalan mulai 24 Februari 1966 dan usai pada tanggal 28 Maret 1966.

Pada Bulan Agustus 1966 secara resmi Presiden Soeharto memandatkan Hoegeng sebagai Deputi Menteri Muda Angkatan Kepolisian. Dalam menjalankan tugasnya ia tidak hanya mengatur dan mengawasi Brigade Mobil (Brimob) tetapi juga berkoordinasi dan mengawasi Kesatuan Polisi perairan dan Udara, Direktorat Tugas umum dan Direktorat lalu lintas.

Pada tahun 1967 diangkat sebagai wakil menteri/Panglima Angkatan Kepolisian (Menteri/Pagak) yang bertugas mengatur operasional Kepolisian Indonesia. Pada awal Mei 1968 sebelum menjadi menteri/pangak Hoegeng dinaikan pangkatnya menjadi Bintang Tiga atau Komisaris Jendral. Selanjutnya 15 Mei 1968 Hoegeng dan Tengku Azis dilantik menjadi Menteri/Pangak dan Wakil menteri/Pangak. 
Berdasarkan keputusan Presiden Nomo 52 Tahun 1969 Presiden Soeharto merubah jabatan Menteri/Pangak dan Wakil menteri/Pangak menjadi Kepala Kepolisian Negara RI dan wakil Kapolri pergantian penyebutan tersebut diresmikan tepat ditanggal 1 Juli 1969 pada hari Bhayangkara (Suhartono, 2013).

Karakter Jendral Hoegeng Iman Santoso Sebagai Teladan Generasi Muda

Jendral Hoegeng adalah salah satu putra bangsa yang menjadi satria keadilan disaat kejujuran sangat minim, dan keadilan di Indonesia semakin mengerdil. Jendral Hogeng mempunyai prinsip hidup sederhana jujur dan tegas. Dan memiliki pegangan hidup yaitu memilih kebenaran daripada kebeneran. Kebenaran adalah susatu yang mutlak sedangkan Kebenaran (dalam bahasa Jawa artinya kebetulan) yang sifatnya situasional dan sesaat. Dan Hoegeng mengatakan bahwa Kebeneran belum pasti suatu kebenaran (Sohartono, 2013 : 68).

Karakter Jendral Hoegeng Iman Santoso yang dapat di teladani generasi muda dan masih relevan di zaman sekarang antara lain:

1. Kejujuran

Anas Sahludin dalam (Muhasim, 2017) mengatakan bahwa jujur merupakan tingkah laku dalam usaha yang membuat dirinya dapan diandalkan dalam tutur kata, perbuatan dan kegiatan. Jendral Hoegeng memiliki sifat jujur dibuktikan dengan saat menjabat sebagai Menteri Iuran Negara Hoegeng selalu mencatat setiap iuran atau pendapatan ke kas negara.

Hoegeng saat menjadi Menteri Iuran Negara tidak mengumpulkan kekayaan untuk kepentingan pribadi. Padahal bisa saja ia menghimpun harta untuk keluarganya dengan menyalahgunakan uang negara atau melukan tindak korupsi. Dan pada saat itu keadaan negara juga sedang kocar - kacir karena merupakan negara yang baru merdeka. Tetapi Hoegeng tidak ingin korupsi bahkan anti korupsi dan Hoegeng tetap memegang prinsipnya untuk menjadi pribadi yang jujur (Suhartono, $2013: 62$ ).

M. Jusuf Kalla juga mengutarakan bahwa Jendral Hoegeng adalah tokoh yang jujur, ia adalah sosok yang sederhana, yang tak punya apa - apa kecuali kejujuran itu sendiri (Suhartono, 2013). Fakta karakter kejujuran Jendral Hoegeng dapat dilihat ketika dia menangani kasus penyelendupan. Kasus penyelundupan ini merupakan kasus yang terkenal pada tahn 1968-1972 yang pelakunya seorang keturunan Cina yang bernama Robby Tjahyadi. Robby Tjahyadi ini merupakan tersangka kasus penyeludupan mobil mewah.

Keistimewaan dari kasus penyelundupan ini yaitu barang - barang yang diselundupkan berasal dari luar negeri dalam bentuk mobil - mobil mewah dalam jumlah yang sangat besar. 
Penyeludupkan mobil mewah ini menyebabkan kerugian negara yang sangat besar, penyeludupan ini memiliki modus operasi yang sangat canggih dengan cara memanfaatkan, memasukan diplomatik. Tim inti penyelundupan ini terdiri dari 3 orang tetapi melibatkan puluhan pejabat tinggi negara. Kegiatan penyelundupan mobil mewah ini berhasil dibongkar oleh Hoegeng yang mengakibatkan beliau tidak disukai dan dipecat dari Kapolri karena berusaha menggali lebih dalam kasus penyelundupan mobil mewah ini (Yusra \& Ramadhan 1993).

Hoegeng adalah seorang yang tidak berhasil disuap, dibuktikan ketika ia bertugas dimedan dengan pangkat Kompol. Beliau membongkar praktek suap menyuap yang dilakukan oleh para polisi, jaksa dengan bandar judi. Barang - barang mewah pemberian bandar judi ia buang keluar jendela. Bagi beliau lebih baik hidup melarat dari pada menerima suap atau korupsi. Prinsip hidup yang baliau pegang ini ia tiru dari manatan wakil presiden Indonesia yaitu Mohammad Hatta.

Fakta lain yang menunjukan karakter jujur Hoegeng ketika ia dihadapkan pada kasus pemerkosaan seorang penjual telur yang bernama Sumarijem di Yogyakarta. Dalam kasus pemerkosaan ini anak seorang pejabat diduga ikut menjadi pelakunya. Beliau langsung membentuk tim khusus untuk pemerkosaan ini diberinama Tim pemeriksa Sum Kuning. Tim ini dibentuk pada bulan Januari 1971. Hoegeng tidak gentar dalam mengusut tuntas kasus ini akan tetapi Presiden Soeharto meminta kasus ini tidak ditangani oleh mereka melainkan dialih tugaskan oleh tim pemeriksa pusat Kopkamtib. Kasus pemerkosaan ini menyebabkan Jendral Hoegeng dipensiunkan dari jabatanya sebagai Kapolri. (Sohartono, 2013).

Hoegeng ketika mejabat menjadi Kepala Jawatan Imigrasi dan menteri Luar Negeri Republik Indonesia ia meminta istrinya untuk menutup toko kembang yang dikelola oleh istrinya. Toko kembang ini merupakan salah satu pengasilan tambahan mereka. Hoegeng tidak ingin orang - orang yang berkepentingan dengan imigrasi memesan kembang pada toko istrinya yang menyebabkan ketidakadilan bagi toko kembang yang lain. Hoegeng juga memiliki ketakutan tersendiri jika toko bunga itu akan menjadi beban bagi dirinya dalam menjalakan tugasnya. Dia tidak ingin orang - orang membeli kembang ditokonya karena jabatan yang diembannya.

Hoegeng memiliki prinsip dalam hidupnya dia tidak akan takut atau gentar menghadapi orang - orang yang berkuasa ia hanya takut kepada Tuhan yang Maha Esa. Pada saat ini karakter jujur yang dimiliki oleh Hoegeng amatlah penting, dan harus diwariskan kepada Jurnal Swadesi, Volume II Nomor 1 (Mei) 2021 
generasi sekarang. Karakter jujur pada zaman sekarang mengalami kemerosotan disegala bidang yang ada di Indonesia tidak terkecuali disekolah yang lingkup lebih kecil seperti siswa yang mencotek ketika mengerjakan tugas. Karakter jujur ini harus di tanamkan kepada peserta didik sebagai bentuk tindakan preventif untuk mencegak korupsi dimasa depan. Peserta didik perlu meneladani sifat jujur dari seorang Hoegeng .

\section{Disiplin}

Sikap disiplin sangatlah penting dan sebagai keharusan bagi setiap orang kapan saja dan dimana saja, sebab disiplin menentukan fluensi manusia dalam meraih sesuatu yang ia inginkan (Ardiansyah, 2013). Disiplin waktu sangat berguna baik disiplin waktu belajar ataupun disiplin saat bekerja. Jendral Hoegeng adalah orang yang disiplin dibuktikan dengan ketika beliau menjabat sebagai Menteri/sekretaris Presidium kabinet dimana pegawai masuk mulai pukul 07.00 dam pulang pukul 14.00, Jendral Hoegeng selalu berangkat lebih cepat yakni pukul 05. 30 bahkan ketika sudah menjadi Kapolri Hoegeng juga masih berangkat lebih cepat dari jam masuk yang ditentukan. Adytia Soesanto Hoegeng (anak Hoegeng) mengatakan dalam (Sohartono 2013) bahwa ayahnya, Hoegeng mempercayai orang dengan ketepatan waktu yang dijanjikannya, karena dengan presisi waktu maka orang dapat memprakarsai sesuatu dengan baik, jika tidak menepati waktu maka sulit untuk melakukan sesuatu, apalagi mempercayai ucapannya (Suharono, 2013).

Hoegeng ketika ia mejabat sebagai Kapolri ia memperjuangkan kewajiban bagi para pengendara dan penumpang sepeda motor menggunakan helm untuk keselamatan. Akan tetapi kebijakan ini ditentang oleh berbagai kalangan masyarakat karena mereka tidak terbiasa memakai helm. Kebijakan Hoegeng ini bertujuan untuk keselamatan pengendara dan penumpang sepeda motor. Kebijakan ini disetujui beberapa bulan kemudian sampai saat ini helm merupakan perlengkapan wajib bagi pengendara dan penumpang. Keberhasilan Hoegeng mewajibkan menggunakan helm membuat nama Hoegeng menjadi populer (Suhartono 2013 : $117-118)$.

Kedisiplinan Jendral Hoegeng sangat penting kita teladani untuk generasi muda karena pada saat ini di Indonesia terdapat budaya ngaret, dimana ngaret ini bermula dari karet yang mempunyai ciri yang elastis dan mudah direnggangkan. Dalam budaya ngaret ini hal yang dimaksudkan adalah waktu. Sebenarnya orang yang mengulur waktu atau orang yang datang terlambat bukan tanpa sebab, hal itu terjadi dikarena banyak orang yang belum bisa memperhitungkan waktu dengan maksimal. Jika kita menjadi orang orang yang tidak tepat 
waktu maka yang seharusnya kita bisa melakukan beberapa agenda tetapi karena ngaret (datang terlambat) agenda yang kita lakukan menjadi terbatas. Orang tua atau pun anak muda di Indonesia sepertinya sudah menganggap ngaret atau datang terlambat sebagai hal yang biasa dan lumrah dilakukan. Sehingga budaya ngaret ini mengakar di masyarakat Indonesia. Kuncinya adalah setiap orang harus bisa memperhitungkan waktu, mengikuti jadwal, dan menghargai waktu agar budaya ngaret dapat dihilangkan (CNN Indonesia 08 Agustus 2019, diakses pada 24 Februari 2021)

\section{Kesederhanaan}

Hidup sederhana merupakan tindakan yang sinkron dengan kondisi yang sesungguhnya (Kemendikbud, 2016). Kesederhanaan Hoegeng terlihat dari fakta ketika ia menjadi Kapolri Hoegeng tidak mempunyai kekayaan apa - apa, apalagi Rekening gendut. Hoegeng hanya memiliki sikap sederhana dan jujur. Ketika Hoegeng menjabat sebagai menteri dan Kapolri keluarganya hidup dalam ekonomi yang pas - pasan, mereka hanya mempunyai rumah sewa yang dibayarnya perbulan.

Ketika menjabat sebagai menteri Hoegeng mendapatkan fasilitas mobil dinas 2 unit, yaitu mobil dinas menteri dan mobil untuk keluarga. Namun mobil untuk keluarga Hoegeng tolak dengan alasan tidak mempunyai garasi untuk menaruh mobil tersebut. Namun karena kebijakan dari setneg maka Hoegeng menerima dan meletakan mobil tersebut di rumah sekertarisnya yaitu Soedharto Martopoespito atau biasa dipanggil pak Darto.

Bukti lain dari kesederhaan Hoegeng adalah Hoegeng pernah menolak pemberian mobil dari Dasaad Musin, beliau adalah pengusaha mobil. Hoegeng dapat mengambil mobil tersebut dengan syarat membawa surat pemberitahuan. Namun Hoegeng menolak dan surat tersebut diberikan kepada temannya sehingga temanyalah yang mendapat hadiah mobil tersebut (Suhartono, 2013). Hoegeng menjabat sebagai wakil Menteri/Panglima Angkatan Kepolisian (Pangak) dan menteri Pangak (kemudian berubah menjadi Kepala Kapolri), Hoegeng menolak pengawalan. Hanya terdapat dua orang ajudan dinas yang bergantian bertugas saat hari kerja dan staf ajudan yang membantunya sehari - hari.

Sebagai pejabat Hoegeng tidak mau aji mumpung atau ketika berkuasa memnfaatkan jabatannya untuk mengumpulkan harta sebanyak - banyaknya. Hoegeng banyak menolak fasilitas terkait jabatannya yang dinilai berlebihan meskipun hal yang dimungkinkan dalam aturan seperti pemberian kavling tanah, rumah, mobil dinas dan pengawalan sehari - hari serta penjagaan didepan rumah. 
Kesederhanaan Hoegeng tidak hanya ada pada dirinya tetapi juga pada anak - anaknya. Anaknya diminta untuk hidup sederhana dan tidak bergantung kepada orang lain. Uang Pensiun ketika Hoegeng berhenti menjadi Kapolri sampai pada tahun 2001 hanya Rp. 10.000 perbulan dan hanya menerima Rp.7.500 karena berbagai potongan. Lalu pada tahun 2001 terdapat perubahan surat keputusan pensiun sehingga mendapat Rp. 1.170 .000 setiap bulannya. Setelah Hoegeng meninggal Istri Hoegeng mendapat separuhnya karena ia pensiunan janda Kapolri (Suhartono 2013: 63). Kesederhanaan tersebut seharusnya bisa jadi teladan agar tidak hidup dalam kesukaran. Sikap Hoegeng yang sederhana, terbuka, jujur dan tak mau kompromi merupakan cerminan sikapnya yang anti korupsi.

Ketika Hoegeng diberhentikan dari jabatan Kapolri, pemerintah menawarkan Hoegeng menjadi Dubes dikerajaan Belgia, Benelux dan Luxeburg (Benelux). Dengan alasan istri Hoegeng Meri, adalah keturunan Belanda dan Hoegeng fasih berbahasa Belanda. Diharapkan dengan menjadi Dubes Kerajaan Benelux Hoegeng bisa menerima. Namun lagi - lagi Hoegeng menolak. Banyak yang berpendapat ketika Hoegeng ditawari jabatan keluar negeri salah satu cara pemerintah Soeharto mengasingkan Hoegeng ke luar Indonesia. Seperti yang dulu pernah terjadi kepada tokoh pejuang Indonesia salah satunya adalah Sutan Syahrir.

\section{SIMPULAN}

Hoegeng Iman Santoso layak sebagai teladan generasi uda agar menjadi generasi jujur, disiplin dan dan dapat hidup sederhana. Hoegeng merupakan putra bangsa yang kejujuran terkenal di bumi Indonesia. Salah satu kebijakan Hoegeng yang masih bisa kita rasakan sekarang adalah penggunaan helm kepada para kendara motor untuk keselamatan.

Dari seorang Jendral Hoegeng kita dapat memperoleh sifat dan dikap yang dapat diteladani seperti kejujuran. Kejujuran sangatlah penting. Beliau tidak gentar dengan apa yang dia lakukan ketika semua hal dilakuakn dengan kejujuran. Serta beliau tidak memanfaatkan jabatan dan kekuasaan untuk kepentingan pribadi. Selanjutnya yang dapat diteladani dari Hoegeng adalah kedisiplinan, pada saat ini sudah sangat sedikit oarang yang disiplin dan menghargai waktu. Banyak masyarakat Indonesia yang sering datang terlambat dalam sebuah aktivitas. Sikap kesederhanaan juga melekat pada diri Hoegeng Iman santoso yang banyak menolak pemberian dari orang lain dan bersyukur dengan apa yang dimilikinya. Sifat dan sikap Hoegeng yang dapat menjadi teladan tercatat dalam sejarah bangsa dan jasanya akan tetap harum di Bangsa Indonesia. 


\section{DAFTAR PUSTAKA}

Ardiansyah, Hanif. 2013. Faktor - faktor yang Mempengaruhi Disiplin Belajar Siswa Kelas XII Jurusan Admistrasi Perkantoran Di SMK NU 01 Kendal Tahun Pelajaran 2012/2013. Skripsi Pendidikan Ekonomi. Universitas Negeri Semarang

CNN. 2019. Pola Pikir di Balik Budaya Ngaret yang Mengakar. Diakses pada 14 Februari 2012

Daliman. 2015. Metodologi Penelitian Sejarah. Yogyakarta: Ombak.

Hasyim. Muhammad. 2015. Konsep Pendidikan Karakter Perspektif Umar Baradja dan Relevansinya dengan Pendidikan Nasional. CENDEKIA: Jurnal Studi Keislaman Volume 1, Nomor 2. From DOI: https://doi.org/10.37348/cendekia.v1i2.11

Kemdikbud. 2018. Konsep dan Pedoman Penguatan Pendidikan Karakter Tingkat Sekolah Dasar dan Sekolah Menengah Pertama. Jakarta : Kementrian Pendidikan dan Kebudayaan

Kemendikbud. 2016. Buku Seri Pendidikan Orang Tua: Menanamkan Hidup sederhana. Jakarta : Kementrian Pendidikan dan Kebudayaan

Muhasim. 2017. Budaya Kejujuran Dalam Menghadapi Perubahan Zaman (Studi Fenomenologi Masyarakat Islam Modern) Jurnal: Studi Keislamaan dan Ilmu Pendidikan Volume 5 Nomor 1 from DOI: https://doi.org/10.36088/palapa.v5i1.78

Ramadhan, Ardito. 2021. Indeks Persepsi Korupsi Indonesia Pada 2020 Turun jadi peringkat 102 di Dunia. Kompas.Com diakses pada 23 Februari 2021

Suhartono. 2013. Hoegeng Polisi dan Menteri Teladan. Jakarta: Kompas Media Nusantara

Yusra, Abrar \& Ramadhan. 1993. Hoegeng Polisi Idaman dan Kenyataan (sebuah Autobiografi) Jakarta: Pustaka Sinar Harapan

Zahro, Mustika.Sumardi \& Marjono. 2017. The Implementation Of The Character Education In History Taeching. Jurnal Historica. Volume 1 Issue 1 from $<$ https://jurnal.unej.ac.id/index.php/JHIS/article/view/5095 